\title{
Oxidative Stress and Neurodegeneration
}

\section{Sandeep Kumar Singh*}

Indian Scientific Education and Technology Foundation, Lucknow-226002, India

Oxidative stress is now accepted as responsible for redox regulation comprising reactive nitrogen species (RNS) and reactive oxygen species (ROS). Its role is critical for the variation of important cellular functions, notably for neuronal cells including astrocytes and microglia, such as ion transport, apoptosis program activation and calcium mobilization, played role in excitotoxicity. Classically oxidative stress is described as an imbalance between production and diminished of ROS and RNS. Oxidative stress implies a situation where reactive oxygen species (ROS), like superoxide $\left(\mathrm{O}_{2}^{-}\right)$, hydroxyl $(\mathrm{OH})$ free radicals and its products are in excess comparison to antioxidant defense system. Oxygen free radicals and other reactive oxygen species (ROS) are common outcome of different biochemical processes in aerobic cellular metabolism $[1,2]$. Free radicals are very reactive and unstable molecules with unpaired electrons in outer orbit. Superoxide $\left(\mathrm{O}_{2}^{-}\right)$, hydroxyl $(\mathrm{OH} \cdot)$, nitric monoxide $(\mathrm{NO})$, hydrogen peroxide $(\mathrm{H} 2 \mathrm{O} 2)$ and peroxynitrite (ONOO-) are well known free radicals and reactive oxygen species in aerobic cellular metabolism. Reactive species were originally considered to be extremely harmful to cells. It is now well reported that redox reaction comprising ROS, is key to the variation of normal cellular functions, notably for microglia and neurons astrocytes, such as ion transport, apoptosis program activation, mitogene-activated protein (MAP) kinase cascade activation and calcium mobilization.

Hydrogen peroxide and peroxynitrite are not readily cause toxicity to biomolecules; further undergo some other reactions to generate free radicals. For instance hydrogen peroxide may further degrade into highly reactive hydroxyl radical via Fenton chemistry or a Haber-Weiss reaction $[3,4]$. Overproduction of free radicals can cause extreme damage to biomolecules like proteins, unsaturated fatty acids and mitochondrial DNA, inflammation, aging, tissue damage and subsequent cellular apoptosis [5]. Apart from their high reactive toxicity they have some biological activities like signal transduction, defense against invading pathogens, gene transcription and regulation of soluble guanylate cyclase activity. In aerobic biological system antioxidant defense system coevolved with oxidative free radicals to counteract [6]. Antioxidants are scavengers of ROS and its precursors. In biological system antioxidant defense system comprises two groups; enzymatic and non-enzymatic antioxidants, In enzymatic antioxidants catalase, superoxide dismutase (SOD) and glutathione reductase and peroxidase and some other supporting enzymes. In non-enzymatic antioxidants like ascorbic acid, vitamin-A, vitamin-E, caroeinoids and polyphenolic compounds are derived from dietary source which directly scavenge the free radicals, in some cases our system itself synthesize some chelating agents to trap the redox metals to prevent free radical production [7]. The brain is one of the famously metabolically active organs in human body, whose sole carbon energy source is glucose. It accounts for $2 \%$ of total body mass and consumes $20 \%$ of total oxygen in a resting individual. Therefore its highly prone to electron leakage in oxidative phosphorylation and reaction of redox active metals like $\mathrm{Cu}$ and Fe with molecular oxygen [8] which cause subsequent reactive oxygen species (ROS) generation. Over production of these highly reactive species cause abnormal protein aggregation and leads to neurodegeneration. Apart from several other genetical and environmental factors oxidative stress is the leading factor in most of the neurodegenerative disorders like Alzheimer's disease, Parkinson's disease.

\section{References}

1. Halliwell B (1994) Free radicals antioxidants and human disease: curiosity cause or consequence? Lancet 344: 721-724.

2. Poulson HE, Prieme H, Loft S (1998) Role of oxidative DNA damage in cancer initiation and promotion. Eur J Cancer Prev 7: 9-16.

3. Markesbery WR (1997) Oxidative stress hypothesis in Alzheimer's disease Free Radic Biol Med 23 134-147.

4. Liochev SI (1999) The mechanism of "Fenton-like" reactions and their importance for biological systems A biologist's view. Met lons Biol Syst 36 1-39.

5. Salganik RI (2001) The benefits and hazards of antioxidants: controlling apoptosis and other protective mechanisms in cancer patients and the human population. J Am Coll Nutr 20: 464-472.

6. Yu BP (1994) Cellular defenses against damage from reactive oxygen species Biol Rev 74: 139-162.

7. Gilgun-Sherki Y, Melamed E, Offen D (2001) Oxidative stress inducedneurodegenerative diseases: the need for antioxidants that penetrate the blood brain barrier. Neuropharmacology 40: 959-975.

8. Halliwell B, Gutterer JM (1999) Free Radicals in Biology and Medicine. Oxford Univ Press Oxford.
*Corresponding author: Singh SK, Indian Scientific Education and Technology Foundation, Lucknow-226002, India, Tel: +91-9473525724; E-mail: sandeeps.bhu@gmail.com

Received September 18, 2017; Accepted October 03, 2017; Published October 10,2017

Citation: Singh SK (2017) Oxidative Stress and Neurodegeneration. J Cytol Histol 8: e119. doi: 10.4172/2157-7099.1000e119

Copyright: (c) 2017 Singh SK. This is an open-access article distributed under the terms of the Creative Commons Attribution License, which permits unrestricted use, distribution, and reproduction in any medium, provided the original author and source are credited. 